\title{
On the problem of nightshade vegetables harvesting in conditions of limited land use and protected ground
}

\author{
Sergey V. Belousov*, Sergey Yu. Onikienko, and Darya M. Klinova \\ Kuban State Agrarian University named after I.T.Trubilin, Krasnodar, Russian Federation
}

\begin{abstract}
The paper is devoted to the analytical justification of nightshade vegetables harvesting in conditions of limited land use and protected ground, both by direct and reusable methods. The article has an analytical research character, which is expressed in the fact that the analysis of the method of nightshade vegetables harvesting is given. The main trend of technology development and improvement of its design to advance the quality parameters of harvesting is identified. As a result of the work done, the conclusion is made about the importance of nightshade vegetables harvesting and in the development of new varieties in the context of modern approaches to the cultivation of nightshade vegetables.
\end{abstract}

\begin{abstract}
All over the world, agriculture is one of the main basic branches of the economy, which ensures the food security of the state. In different countries of the world, you can note the variety of cultivation of agricultural crops. In the last 10-15 years, Russian agriculture has been developing dynamically. The volume of agricultural exports has been practically restored to the level of Soviet times. The domestic market is fully provided with its own grain, potatoes, and nightshade vegetables. In the coming years, the issue of providing with meat of cattle, pork and poultry should be resolved [1].

The government of the Russian Federation is developing state programs aimed at solving existing problems in line with modern trends in agricultural development and promising population growth. In recent years, according to the Food and Agriculture Organization of the United Nations, more than one billion people suffer from hunger in the world and this figure increases from year to year. According to the same organization, by 2050, the world's population will be close to 10 billion people, and there will be a reduction in fertile and arable land. In line with these forecasts, we can conclude that the demand for agricultural products such as cereals and vegetables will increase, and the demand for animal feed products will increase.

Mechanization of operation in protected ground and conditions of limited land use requires special measures and conditions. The designed facility must meet its technical characteristics and, most importantly, the dimensions of the structure or place where it will be used. When using mechanization units in protected ground conditions, it is not recommended to use power units with internal combustion engines. However, the nature of
\end{abstract}

\footnotetext{
* Corresponding author: sergey belousov 87@mail.ru
} 
the impact of working bodies under processing, they should be similar to those applicable in the open ground, and be as automated as possible [2].

Currently, the following types of protected ground structures are observed:

- bedding cultivation of crops with heating;

- ground greenhouses with heating;

- spring plowing of greenhouses with combined heating systems (artificial heating and solar heating);

- single- or double sash hotbed greenhouses with combined heating system

- heated ground (it is gaining popularity year by year in the conditions of cultivation in a temperate climate).

Types of constructions with limited land use:

- gardens and vineyards in private plots;

- palmetto gardens;

Works on cultivation of agricultural crops in all zones and types of designated structures and places are carried out all year round. For example, the organization of horticulture and tobacco production is based on an extremely strict combination of areas, agro-technical and biological terms of interaction of open and protected grounds and according to leading research institutes, up to $50 \%$ of all vegetables are grown by seedling method. In this regard, different types of structures usually complement each other. So greenhouses yield year-round, hotbeds give an early harvest (seasonality), and grown in this way gardens and vineyards give a quick and high-quality harvest [2,3].

In growing of seedlings, it is also necessary to observe agro-technical deadlines, since some products from greenhouses and hotbeds are carried to the open ground, and it is necessary to observe a smooth transition of the output of seedlings from favorable conditions to open ground at the right time.

Due to the variety of cultivated crops, there are many different technical means of operation in protected ground conditions. These units are not classified according to technical criteria and working bodies, but according to the technological processes that they can provide.

It is also possible to classify the means of mechanization for operation in conditions of limited land use separately, starting with the laying of gardens and vineyards and ending with their care and harvesting [4].

A special place is given to harvesting crops in these conditions. Technical units that are widely used in field conditions on large areas are not suitable due to their size. However, the physical and mechanical properties of plants that are grown under protected ground conditions and in conditions of limited land use do not differ from those that are grown in the open ground.

The impact of the working bodies of agricultural machines at the time of harvesting is similar in protected ground. However, the principle of harvesting is radically different. If we consider the physical and mechanical properties of the most common crops, such as sweet peppers, eggplant, and of course, tomatoes, we can make the following conclusions.

The growth of pepper, its development and fruiting has a number of specific features, so, it is crucial to analyze the physical and mechanical properties of the plant and fruit, as well as existing varieties and growing technologies that affect these properties to solve the problem of harvesting. Sweet pepper is a member of the Solanaceae family, but the crop is used as an annual plant during crop rotation [5]. Fruits are located in the fork of branching shoots by ones, rarely twos. The shape of the fruit in common varieties is cone-shaped, elongated cone-shaped, prismatic. Fruits up to $100 \mathrm{~mm}$ height and $50 \mathrm{~mm}$ in diameter are to be considered standard for canning industry and the total mass of the shaping fruit is up to $45-50 \%$ of the total mass of the plant. 
Eggplants are in high demand on the market and mainly are used for the canning industry, restaurant business and home cooking. Increasingly, you can see the appearance of a large variety of varieties and sizes on the market. The size of the eggplant fruit is important under mechanized harvesting, but similar conditions can be applied to it as under sweet pepper harvesting [6].

For special machine harvesting, some technical schemes are used for placing plants in the field in the open ground, which is not suitable for the use in limited land use conditions. However, the physical characteristics of common tomatoes plants cultivated under protected ground conditions are practically the same as those cultivated in fields. An important factor of mechanical harvesting of tomatoes are properties of tomatoes to damage, the so-called strength characteristics, breaking force of the fruit from the stem, strength of the connection of the plant with ground, breaking force of the stem, lodging, uniform ripening, transportability, resistance to storage.

Based on the results of market analysis and materials that are publicly available, it can be concluded that mass harvesting of nightshade vegetables around the world is carried out either manually or with the use of small-scale mechanization. However, many companies are working on the design of machines and mechanisms for single-use and reusable harvesting of such crops. It is worth noting that the greatest success in this operation has been achieved by scientists in the CIS countries, Europe, and the United States [7].

In Russia, the problem of harvesting and nightshade vegetables cultivation is associated with the names of such scientists of Kuban State Agrarian University as Viktor Ablikov and Ruslan Gish. They conducted in-depth researches in mechanized harvesting and development of new varieties of nightshade vegetables.

Manual multi-time harvesting of nightshade vegetables consists of repeatedly harvesting fruits as they mature, while sorting and culling diseased and rotten fruits and packing the part of fruit in boxes or nets to be sent to retail chains or for processing. Special boxes, buckets and nets are used as containers under manually nightshade vegetables harvesting. The main disadvantages of this method are the following: a shortage of labor force, high labor costs and a high degree of fruit damage. All these factors determined the reduction of the area under this valuable crop.

The method of partially mechanized harvesting up to now has been the most common, it allows you to mechanize the harvesting process partially and increase the productivity of the process by 1.5-2 times, but it does not exclude manual labor, this method can be attributed to reusable method [8].

The use of small - scale mechanization units, such as wide-grip conveyors, harvesting platforms, and others, is perfect for it. It allows to increase labor productivity by intensifying the process of harvesting and transporting of products, as well as by introducing progressive forms of labor organization - container packing and transportation, and mechanization of the process of container transportation [9].

Machine harvesting of nightshade vegetables currently applicable only in the cultivation of crops in open ground and using harvesters with minimal manual labor is certainly appropriate and promising. This harvesting technology is increasingly used in countries that produce nightshade vegetables, providing a cheap product, stimulating the expansion of sowings of this valuable crop. There is a one-time and reusable machine harvesting.

Undoubtedly, the cultivation of nightshade vegetables in various conditions is a promising trend and requires a special way of cooperation between breeders and engineers. So back in 1987, according to Dale E. Marshall, a member of the American Association of Agricultural Producers, about 75 million tons of sweet pepper alone were grown in the world on an area of 1 million hectares [10].

Over the past three decades, there has been a significant increase in interest and research on mechanized harvesting of not only sweet peppers, but all nightshade vegetables. During 
this time, a huge number of experimental types of harvesters were made. Many different research institutions, design bureaus and factories were involved in this work on a global scale.

At the turn of the century, a promising scientific school of selection and harvesting of nightshade vegetables was created in Kuban State Agrarian University. Students of this scientific school continue researches in the context of modern approaches to the cultivation of nightshade vegetables.

\section{References}

1. Belousov S.V., Belousova A.I., Experimental researches of plant protection means, MATEC Web of Conferences 2018. C. 05002.

2. Belousov S.V., Pomelyayko S.A., Novikov V.V., Design of the universal agricultural working body and study of its pa-rameters, MATEC Web of Conferences 2018. C. 05006 .

3. Belousov S.V., Gusak E.S., Theoretical justification of fruit separation process by a planetary fruit separator, E3S Web of Conferences 2019. C. 00056.

4. E. S. Bosoy, I. I. Smirnov, O. V. Vernyaev, E. G. Sultan-Shah, Theory, construction and calculation of agricultural machines [Text] /. - Moscow: "Engineering", 1978 - 568 p.

5. Belousova A.I., Moiseev A.V., Experimental researches of determination of degree of interaction of a working organ with the object of treatment in plant growing, MATEC Web of Conferences 2018. C. 05001.

6. Goryachkin, V.P. Collection of ossions: in 3 t. / V.P. Goryachkin; by ed. action tsp VASHNIL prof. Dr. S.-H. Sciences ND Luchinsky. - 2nd ed. - M .: Kolos, 1968. - 455 p.

7. Belousova A.I., Moiseev A.V., Experimental researches of determination of degree of interaction of a working organ with the object of treatment in plant growing, MATEC Web of Conferences 2018. C. 05001.

8. Papusha S.K., Bogus A.E., Konovalov V.I. , Interaction of rotary working body of roller type with the object of processing, MATEC Web of Conferences 2018. C. 05007.

9. Donchenko L.V., Belousova A.I. Automation of technological process of obtaining pectin , E3S Web of Conferences 2019. C. 00062.

10. Papusha S.K., Belousov S.V., Bogus A.E., Konovalov V.I. , Theoretical studies of the tobacco stalk interaction with the leaf-separating unit, International Journal of Applied Engineering Research. 2016. T. 11. № 8. C. 5610-5613. 